\title{
Entrepreneurship as an IEEE Workforce Development Theme
}

\author{
Tinus Stander \\ Carl and Emily Fuchs Institute for Microelectronics \\ Dept. Electrical, Electronic and Computer Engineering \\ University of Pretoria \\ Pretoria, 0002, South Africa \\ tinus.stander@ieee.org
}

\begin{abstract}
The IEEE is currently planning an extensive workforce development (WFD) programme through its volunteer and associated networks. Together with environmental scans, potential learning areas and contributing partners are being solicited. The Institute of Physics has an established workshop in Entrepreneurship for Scientists and Engineers, which may partially fulfil this role. This paper describes the format and content of this workshop, constructively evaluating it keeping in mind metrics relating to WFD. Future value-adds for IEEE involvement are identified.
\end{abstract}

Keywords - Workforce development; entrepreneurship;

\section{INTRODUCTION}

Since its inception, the IEEE has advocated professional development among its members, but especially its volunteers, a necessary component of being universally recognised for the contributions of technical professionals in improving global conditions [1]. Although a stated goal, this concept has only recently been formalised by the establishment of a Workforce Development (WFD) working group in 2012, as a volunteer development drive. While WFD has several thrusts, in this paper, an entrepreneurship workshop is being proposed analogous to the well-known IEEE Teacher In-Service Programme (TISP) [2] programme aimed at the development of pre-university educators/teachers. The vision of this working group is that, by 2018, the IEEE will be recognised as the principal facilitator of Engineering, Computing and Technology (ECT) education, training and capacity development in Africa.

Two key views of this development programme are that it needs to equip volunteers holistically for the ECT environment, without establishing novel programmes or schools itself. The former involves significant development of non-technical skills, one of which is an understanding of entrepreneurship and intellectual property in an ECT environment. The latter, on the other hand, requires partnership and collaboration to achieve this goal.

In recognition of this need among their own members \& partnering organisations, the Institute of Physics (IoP) have hosted fourteen Entrepreneurship Workshops for Scientists and Engineers globally [3], the latest of which was hosted in Durban, South Africa, on 20 - 24 May 2013 [4]. This paper presents an overview of the nature, content and format of this

\author{
Saurabh Sinha \\ Executive Dean: Faculty of Engineering and Built \\ Environment \\ University of Johannesburg \\ Johannesburg, 2006 \\ South Africa \\ ssinha@ieee.org
}

event, and constructively evaluates it within the context of WFD as a possible initiative to support the WFD objectives.

\section{WORKSHOP THEMES}

The workshop covered a wide range of themes related to Entrepreneurship and related concepts, a brief overview of which is presented below.

\section{A. Nature of engineering and scientific entrepreneurship: \\ Commercialisation of ideas}

The primary focus of this workshop was establishing the knowledge and skills required to apply entrepreneurial principles to chief product of engineers and scientists, namely innovation. This was a key differentiation between this workshop and a more generalised entrepreneurship workshop, and was stressed throughout the event. Several sessions dealt with specific questions relating to the commercialisation of innovation, from basic research all the way through to the delivery of a product to a mature market, including the assessment of technology readiness levels (TRLs)

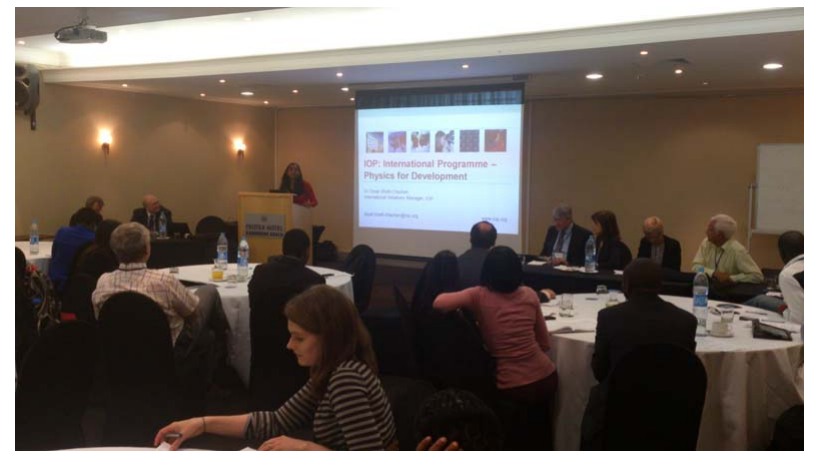

Fig. 1: Workshop in progress. Note the panellists at the front and the delegates seated in groups

Significant emphasis was placed on identifying a product from an idea, identifying a suitable business model and establishing suitable financial and marketing metrics. Other options, such as licensing or marketing intellectual property (IP) (as opposed to the marketing of a developed product) were also illustrated, as well as the decision making process involved in finding a profitable end state. 


\section{B. Intellectual Property}

Where the product is innovative, the protection of IP is paramount. Different concepts and forms of IP protection, as well as practical steps and time scales, were discussed in detail over numerous sessions. This included patents, trademarks, copyright and the preservation of trade secrets. Representatives of a leading local IP law firm discussed the procedures and pitfalls of local and "global" patenting (patent cooperation treaty), provided an overview of the statutory frameworks and highlighted several distinct avenues to achieve IP protection. The importance of an effective IP policy and strategy was stressed throughout. A brief overview of the legal documentation involved in establishing a technology start-up was also presented.

\section{Financial literacy and planning}

Apart from a brief introduction to financial terms and concepts, significant time was spent on effective financial reporting. Although basic, most technical delegates were quite unfamiliar with these concepts, of which a basic grasp is essential in understanding business development. This was presented within the context of effective financial presentation skills (both in person and through the compilation of effective financial plans), especially to prospective investors. This basic financial literacy is an essential requirement between bridging the chasm between innovation and investment. Basic financial planning techniques, such as sales forecasting, cash flow planning and enterprise valuation, were also illustrated.

\section{Obtaining and managing investment}

A significant portion of the workshop was devoted to equipping the technology entrepreneur with the necessary tools and knowledge to obtain financing for his or her enterprise. This was done with several scenarios or development stages in mind, ranging from financing innovations in research phase up to market-ready products. Specific avenues for investment within the local context, from both public and private sources, were presented, with sufficient contacts and context to assist the entrepreneur in approaching these avenues with confidence. Significant emphasis was also placed on divestment or "exit strategy" options suited to the entrepreneur's desired level of involvement in the eventual commercial enterprise.

\section{E. Marketing}

A "soft skill" often understated in training technical professionals is marketing. The workshop dedicated a session to basic marketing skills and practice, identifying target markets and estimating market size and value. This was presented within the context of compiling a successful business plan that would attract investors. The importance of effective management policies, but also the assembly of effective management teams was deliberated.

\section{F. Management planning}

Delegates were instructed on the importance of effective management policies, but also the assembly of effective management teams. This included a critical evaluation of inhouse and outsourced management functions, focusing on the contribution of core efficiencies to achieve a successful enterprise.

\section{G. Communication and Presentation Skills}

A critical skill in innovation entrepreneurship is the ability to extend the innovator's communication and presentation skills beyond the technical realm into finance, marketing and basic legal matters. This training was addressed in a dedicated session, but also stressed throughout the workshop by all of the speakers. Specific techniques to stating a business case were covered, as well as basic techniques of communication in negotiation.

\section{H. Furthering Entrepreneurship Education}

Since the majority of delegates had ties with higher education institutions (HEIs), the final session of the workshop equipped delegates on how to establish entrepreneurship as a taught course at their own institutions. They were presented with a sample curriculum, compiled by the IoP based on the workshop content, and briefed on its application. The need for entrepreneurship training in science curriculums was stressed throughout.

\section{WORKSHOP FORMAT AND STYLE}

Key to the successful presentation of the workshop is its presentation and format, as to facilitate effective learning.

\section{A. Interactive Nature}

Although the workshop sessions were structured around presented lectures, the floor was open to group discussions continually. This interactive nature allowed the speakers to pursue specific topics relevant to the audience, with other speakers and workshop attendees being attracted to discussions. Furthermore, most lectures concluded with group assignments and short feedback sessions.

The workshop itself was concluded with a formal feedback session, during which attendees could provide feedback in an open forum. This was done in addition to feedback questionnaires collected upon conclusion of the workshop. The feedback was considered as favourable, however work beyond such a workshop is the ultimate "tool" to evaluate success. The proposed IEEE involvement is likely to approach the workshop with following up beyond the event and in this way measuring success.

\section{B. Case Studies}

A critical success factor in the presentation of the workshop was the focus on case studies. These were either organically included in topic-specific presentations (IP, investors, etc.) or presented as sessions in their own right. The latter were particularly insightful, as these were presented by the original innovators themselves, with critical analyses of context, pitfalls and success factors. Several local guest speakers were also invited to present their case studies, making these locally relevant.

\section{Team Project}

Delegates were divided into teams on the first day of the workshop, and tasked to present a start-up financing 
presentation at the conclusion of the workshop with one of the workshop presenters assigned to each group as a mentor. Each day the groups were allowed a few hours to work on the presentation, adding content relating to the sessions of the day (eg. financials, marketing plan, technology readiness assessment, etc.). This project was not only an invaluable networking tool among delegates, but also gave them a feel for applying the workshop principles in practice. At the end of the workshop each group had 10 minutes to present their projects, with 10 minutes of Q\&A with the workshop speakers serving as panellists.

\section{Locally Relevant}

Although principles were discussed in general terms, the application of those in local contexts was stressed throughout. To this end, local guest speakers were invited to present case studies, local governmental and private entities were represented as financing opportunities and delegates were briefed on IP legislation by local experts. The local relevance really empowered delegates to pursue commercialisation opportunities of their innovations, arming them with specific local knowledge and giving them confidence to take steps in being entrepreneurial about their research.

\section{SPEAKERS}

The workshop, although organised by the IoP and the SA Institute of Physics (SAIP), was facilitated by speakers from mostly outside the IoP. The speaker line-up was selected to include a range of industry experts, including:

- Corporate communications directors

- Innovation commercialisation consultants

- Financial directors

- Inventors and entrepreneurs, both from Higher Education and other sectors

- Intellectual Property practitioners

The instructors were assisted in some sessions by local South African speakers, including representatives from the local public sector, local entrepreneurs and academia, local IP attorneys and local venture capital managers.

\section{POST-WORKSHOP ACTIVITIES}

It was the stated goal of this workshop that participants were empowered and guided to be entrepreneurs afterwards, in light of which some measures were undertaken to facilitate this ongoing process. This is, however, one aspect of the workshop where further involvement by the organising body would have added significant value. The current measures include:

\section{A. Further use of conference website}

The conference website was employed, after the conclusion of the workshop, as a repository for speaker notes and contact details. Participants were also encouraged to share their own material and notes in this forum.

\section{B. Pursuing networking links}

Attendees were encouraged to network among themselves using professional or social media, to preserve ties established during the workshop.

\section{Higher Education Curriculum}

A DVD with a full semester curriculum was distributed to all delegates, to enable them to establish entrepreneurship courses at their own institutions. These include detailed course notes, assignments and assessments.

\section{IEEE INVOLVEMENT VALUE-ADDS}

This workshop may benefit from future IEEE involvement through a number of unique value-adds the IEEE, as the world's largest technical society, could provide.

\section{A. Access to speakers}

The IEEE has access to a network of over 40,000 volunteers, of various disciplines and with global reach. This network will facilitate not only to attract speakers from a wide range of technical and commercial backgrounds, but also providing local expertise wherever workshops are hosted. Sub-networks to leverage within the IEEE include volunteers from the Technology Management Council.

\section{B. Support networks for workshop development}

Through its global network of volunteers, the IEEE can also facilitate networking between attendees and mentors, not only at the workshop, but also after the workshop wherever delegates return to. The model could be analogous to IEEE's mastery of the TISP, i.e. a model to "train the trainers/volunteers." Such an approach would provide a more stable platform for workshop follow-up activities, having local experts and advisors in place as soon as delegates return from the workshop. The IEEE volunteer network could also be harnessed effectively as local instructors for further workshops globally, allowing for organic growth of this training programme. This approach could be an opportunity for emerging IEEE sub-sections or sections in Africa, where concepts such as incubation associated to HEIs is less developed.

\section{C. e-Learning Resources}

The IEEE has at its disposal several e-Learning resources (IEEE eLearning library), through which further training and mentoring post-workshop can be facilitated. This will add significantly both to this event as an IEEE WFD activity, but also to further development of entrepreneurship globally.

\section{CONCLUSION}

Entrepreneurship is a key skill in the development of engineers and technical professionals. The IoP currently has an effective workshop programme to facilitate this development. Future IEEE collaboration will allow this event to reach an even wider audience, catering for various IEEE designated fields of interest, with specific content focus, as well as allowing for more effective post-event interaction and development. 


\section{ACKNOWLEDGMENT}

The authors wish to thank the Dr Dipali Bhatt-Chauhan from the IoP for her background information in the compilation of this paper. The primary author furthermore extends his thank to Tara Wisniewski, IEEE Director: Social Innovations, for financially enabling the primary author to engage with the IoP.

\section{REFERENCES}

[1] "IEEE Vision and Mission", (available online) http://www.ieee.org/about/vision_mission.html

[2] "IEEE Teacher In-Service Program (TISP)", (available online), http://www.ieee.org/education_careers/education/preuniversity/ tispt/index.html

[3] P. K. Jain, and D. Bhatt-Chauhan, "Entrepreneurship Education for Scientists and Engineers in Africa", Proceedings of the Second Science with Africa Conference, Cape Town, pp. 173 178, 2010.

[4] "Entrepreneurship Workshop for Scientists and Engineers", (available online), http://indico.saip.org.za/conferenceDisplay.py?confId=31 